\title{
NOTES ON BIRDS OBSERVED AT GUANICA LAGOON, AND ITS VICINITY
}

\author{
By Harry A: BeAtTy \\ Constitution Hill, Christiansted, St. Croix, Virgin Islands of U. S. A.
}

During my residence at Santa Rita from November, 1924 to November, 1925 I availed myself of every opportunity to visit the lagoon. The lagoon presented a vast expanse of water which had collected during the few but unusually heavy rainfalls for this region. Although the lagoon has been up to four feet in depth at different times, it was very nearly dry during 1924 until the late rains of that year and 1925 raised the depth indicator to approximately three feet. Being almost of equal depth throughout, due to the fact that the lagoon's floor is perfectly level and very firm, added greatly to the pleasures of wading. I was told of large flocks of migrant ducks which were occasionally shot by employees of Guánica Central, but I never saw any. Observations on a number of birds that I observed follow.

1. PODILYMBUS PODICEPS ANTILLARUM Bangs. Antillean Grebe.

On February 1, 1925 I located a nest with one egg; by February 20 there were five eggs. March 9 as I approached the nest I glimpsed a parent bird peeping at me from among the pond grass. The nest, which it had just left, was a heaped-up mass of rotting vegetation raised four inches above the water's level, with a depression in the center. Examining the nest, I found only three eggs in it. Suspecting that the other two had hatched, I remained perfectly quiet, but had not long to wait until I heard the unmistakable "peep-peep-peep" of a young bird. Ascertaining the exact spot from which the sound came, I saw the little rascal as it propelled itself swiftly through the crystal water, using both legs together, after the fashion of frogs. The poor little chick tried its best to reach the opposite side where safety was assured, but the distance proved too great, and it bobbed up exactly as a large cork would, floating with only its head and rump above the surface, its legs spraddling out behind, and gasping for breath. I leaned over and was about to pick it up when, in spite of its exhausted condition, it again tipped forward and was heading for parts unknown, but it was unable to proceed for more than a foot. I picked it up, and its calls soon encouraged the second chick 
to emerge from hiding. Holding both chicks in my hands, I forced them to utter their baby cries by tapping lightly against their breasts with my forefinger. I was about to turn them free when my efforts were repaid in a peculiar fashion. From somewhere among the pond grass a peculiar sound rent the stillness, followed instantly by a spray of water which went several feet into the air. The parent bird then stuck its head above the surface of the water within ten feet of me and gave another of its peculiar cries. Then ducking its head beneath the surface it tipped up, sending a shower of spray into the air with its feet and making a noisy splash with its wings. It continued these stunts for several minutes and finally disappeared. The call can be easily imitated, when once heard, by saying "Pluke" while attempting to whistle it at the same instant; a low note with plenty of volume. One chick was about two days older than the other, and when swimming on the surface of the water it used its legs alternately.

February 8, 1925 I found a nest and three young; a nest and two eggs, $1.69 \times 1.13$, and $1.33 \times 1.13$ inches; and a nest and five eggs, $1.56 \times 1.19 ; 1.56 \times 1.19 ; 1.50 \times 1.19 ; 1.62 \times 1.25$, and $1.50 \times 1.13$; note the irregularities in the measurements of these eggs. The eggs vary from greenish blue to pale blue shells with a white chalky covering which is easily scratched particularly when the eggs are fresh. The eggs soon become nest-stained. On February 19 I found a nest and four eggs; the next day it contained five eggs, four of them nest-stained, and apparently the fourth had been deposited several days before the fifth, which was fresh and white in color with a bluish overeast. The nest was a floating mass of decaying grasses and algae gathered from the bottom; it measured 1 foot in diameter by 2 feet in depth, the highest part being only three and a half inches above the water level, with a concavity of about one inch in the center, and the eggs actually lying on the saturated bottom. On leaving the nest the parent bird always completely covered the eggs, oftimes with wet material hastily snatehed from the side of the nest. One nest that I located contained three young birds. By the difference in their sizes the oldest chick must have been about two days older than the second.

2. ARDEA HERODIAS ADOXA Oberholser. West Indian Great Blue Heron.

The first time that I observed Great Blue Herons was on June 18; 1925. I had been out riding before dawn, and passing by the lagoon I saw, first, four of them sailing on set pinions as they came to rest 
at the edge of the water. Having noticed that they had come from behind me I looked back and saw two more slowly winging their way towards the lagoon. When I rode away I counted nine birds scattered about the lagoon. All of them came from beyond the hills of the interior. I never observed any of them on the return flight, which was probably under cover of darkness.

3. CASMERODIUS ALBUS EGRETTA (Gmelin). Egret.

On March 14, 1925 I saw two Egrets. They were very shy and kept a considerable distance apart.

4. BUTORIDES VIRESCENS MACULATUS (Boddaert). West Indian Green Heron.

February 25, 1925 I searched the isolated trees near the lagoon for Green Heron nests and located two. Both of them were placed in tamarind trees, about twenty-five feet from the ground, and each contained two eggs.

5. POECILONETTA BAHAMENSIS BAHAMENSIS (Linné). Bahama Duck.

I never saw any ducks other than Bahama Ducks and a pair of Ruddy Ducks, which appeared, by their actions, to be nesting. During the month of December, 1924 I observed only four pairs of Bahama Ducks and they kept together. April 30, 1925 I received a female and two male Bahama Ducks which had been shot on a small fresh water pond overgrown with "rushes" lying near the coast on the outskirts of Ensenada.

\section{PORZANA FLAVIVENTER HENDERSONI Bartsch.} Yellow-bellied Rail.

In a patch of water plants on March 14, 1925 my attention was attracted by an unfamiliar sound. I froze in my tracks, and tried to associate it in my mind with others quite similar which I had heard. It was a single note, uttered once only, the first and last time I ever heard it. It was a softly whistled high pitched "peep" with a distinetly musical quality, entirely different from the familiar "peep" of the young grebe. Looking steadily in the direction from which the call came, almost at the same instant, I saw two Yellowbellied Rails, one behind the other, seurrying across the broken and rotting vegetation, dodging behind leaves, and they were soon lost to sight. I raced after them, and no doubt would have forced them to seek safety by flight, but on reaching the spot where I had first seen them I found a nest with five eggs, and gave up the chase. The nest 
was made of water grass neatly and compactly woveu together, with no lining, and placed in the center of one of the water plants (Pistia), being held in place merely by the strength of the five upright green leaves, there being no visible evidence of any attempt to attach the nest. The nest measured 4.0 inches across the top by 5.25 in depth; the eavity 2.75 inches in diameter by 2.40 in depth, the lower end touching the water. Three of the eggs measured $1.09 \times .82$, and two of them $1.11 \times .82$ inches. They were uniform in shape, with one end slightly tapered. The ground color was glossy whitish cream, with large dark brown and blackish spots sparsely and evenly distributed over the shell, becoming fewer towards the smaller end. I marked the location of the nest, and on March 17 returned, but found the nest empty, apparently robbed, as the trampled "lanes" through the water grass remained as unmistakable evidence of the recent passage of nest-robbers.

7. GALLINULA CHLOROPUS PORTORICENSIS Danforth. Antillean Gallinule.

On March 14, 1925 I found a Gallinule's nest with five eggs, the only nest of this species that I observed. It was in a patch of water plants. Three of the eggs measured $1.76 \times 1.28$ inches, and two of them $1.80 \times 1.28$ inches.

\section{FULICA CARIBAEA Ridgway. Caribbean Coot.}

Coots were very common on the lagoon. I estimated that there were at least 5,000 birds, and apparently they remained throughout the year. The first nest I found was on January 10, 1925. It contained two eggs, each $1.87 \times 1.25$ inches. A nest on January 30 contained one egg, $1.87 \times 1.28$. A nest on February 3 contained one egg $1.87 \times 1.28$ and three eggs $1.94 \times 1.28$. On February 5 a nest had two eggs $1.94 \times 1.28$. Note that although the eggs vary in length they all agree in their diameter. By February the breeding season was well advanced. One morning I counted sixteen nests within a radius of 100 feet, all of them eompleted and either ready to receive the eggs or else they had been robbed before the full complements were deposited. On February 21 I located six nests, all of them within a hundred yards from the lagoon's edge, made of grasses, and placed in beds of water grasses, the bottom of the nests being more or less level with the water. Nest and 5 eggs, $1.94 \times 1.31 ; 1.87 \times 1.31$; $1.87 \times 1.31 ; \quad 2.0 \times 1.31 ; 2.0 \times 1.31$. Nest and 7 eggs, 4 eggs $1.37 \times 1.25 ; 3$ eggs $1.44 \times 1.25$. Nest and 6 eggs, 3 eggs $1.87 \times 1.25$; 3 eggs $1.81 \times 1.25$. Nest and 4 eggs, 2 eggs $1.81 \times 1.28 ; 2$ eggs 
$1.75 \times 1.28$. Nest and 5 eggs, 2 eggs $1.94 \times 1.31 ; 2$ eggs $1.87 \times 1.31$; $1 \mathrm{egg} 1.81 \times 1.28$; one egg is smaller in diameter. Nest and 6 eggs, 3 eggs $1.87 \times 1.31 ; 2$ eggs $1.81 \times 1.31 ; 1$ egg $1.75 \times 1.31$. It is interesting to note that all the eggs in a set have the same diameter measurements, excepting one set, while their lengths vary. I noticed in three instances that the eggs had been almost concealed with grasses, but also noticed that these nests were placed in broad patches of water grass and three or four feet from the open water, which leads me to believe that the parent birds involuntarily carried loose pieces of dead grass, attached to their long toes, into the nests, where they remained, apparently by the birds' indifference. On March 14 a diligent search revealed many nests, but not one with even a single egg.

\section{PAGOLLA WILSONIA WILSONIA (Ord). Wilson's Plover.}

May 16, 1925 I found the nest of a Wilson's Plover with three eggs. The following day they were hatched, and the three chicks running about. This nest was near the lagoon on a bank of earth, and the parents were the only birds of this species observed in the vicinity.

10. OXYECHUS VOCIFERUS RUBIDUS Riley. West Indian Killdeer.

On June 10, 1925 I saw a pair of Killdeers followed by three newly hatched chicks. They kept to the open pasture, and far from the lagoon.

11. HIMANTOPUS MEXICANUS (Müller). Black-necked Stilt.

May 14, 1925 I found the nests of four pairs of Black-necked Stilts with four eggs in each, at the edge of a small fresh water pond near the Bay of Guánica. The nests were made of short pieces of coarse sticks placed in depressions among the short grass. May $17 \mathrm{I}$ found a nest with four eggs about 400 yards from the lagoon. On the 26th I found three chicks and one egg in the nest, and both parent birds in attendance. The following morning I found the four chicks hiding in the grass and both parent birds were frantic in their efforts to keep me from the vicinity. That afternoon I again passed the locality, and to my great surprise, the Stilts were nowhere to be seen. The site was an open pasture, studded here and there with small clumps of cactus; it was impossible for them to remain here without being seen. I gave considerable thought to their disappearance, and came to the conclusion that the chicks had either been devoured by a roaming mongoose or that the parent birds had led them 
off toward the water. Early the following morning I rode by the lagoon, and sure enough, there was one of the adults making a great deal of noise. Dismounting, I commenced to search among the tufts of grass with high hopes of finding a chick. After searching for about two minutes I stepped into a clearing, bare of grass and broken up with the tracks of cattle, and scanned the air for the other adult Stilt, but it was nowhere in sight. Taking a step with the intention of continuing the search, what should I find but a chick flattened against the ground, and lying in the mark of a track, at the point of my boot. A Stilt appeared in the distance, coming from the site of her nest and flying low over the tall grass. I watched her as slowly she winged her way towards me, where I was squatting, and presently passing on my right I noticed a dark object hanging limply from her bill. As she alighted about twenty yards from me, I ran swiftly towards her, taking advantage of the clusters of reeds to hide my approach, and bursting suddenly upon her she flew up, very much frightened, while a little chick, too scared even to move, remained flattened against the ground. I took it up and set it down again, and off it ran, twisting about so swiftly that I made several futile attempts to recapture it before I was successful. The parent Stilt had brought her chick to the water by taking hold of it by the neck, its head protruding from her bill on one side, while its little body dangled from the other.

\section{CHLOROSTILBON MAUGAEUS (Audebert and Vieillot). Porto Rican Emerald Hummingbird.}

March 9, 1925 I located a nest of this hummer containing a single pure white egg, $0.50 \times 0.33$ inches; the nest was made of wild cotton, and was 1.5 inches in diameter by 2.0 in depth, the cavity being .85 inch in depth by .75 in diameter. It was placed about five feet above the ground on the slender waving branch of a large tree. The female left the nest eight times during one half hour for short periods, making excursions among the barrel cacti, gleaning spiders from their webs among the spiny cacti, and nectar from their blossoms. On March 16 a newly hatched young was in the nest. Upon my approach the female came towards me, remaining suspended before my face on blurred pinions. I made a quick grab at her, but my speed was like slow motion in comparison with hers as with a buzz she was off. Standing motionless with my face a foot from the nest, she suddenly appeared, and hanging in the air, two feet away, looked at me suspiciously for a moment, then rising slowly for several inches, she advanced with a sharp buzz, checked herself, and deliberately 
started to fly backwards and slightly downwards, still facing me. With another buzz she alighted on the nest with her breast towards me. Then she began acting as though very sleepy, but proved to be very much awake when I attempted to touch her on the crown. I noticed that every time she settled on the nest to incubate it was done without first alighting on the rim, and that when leaving she flew off either upward or directly forward. Several times she fed the chick while suspended in the air on blurred pinions, stretching her neck downward and placing her bill into the throat of the little fellow as she regurgitated a mass of predigested insects and nectar. On April 7, after a period of 23 days, the chick left the nest.

April 5 a nest, with a single egg, made of wild cotton, and placed fifteen feet above the ground on the slender branch of a "Roma" was found.

March $1 \mathrm{I}$ found an incomplete nest of this hummer attached to a slender branch of a mango tree four feet above the surface of a stream.

\section{TODUS MEXICANUS Lesson. Porto Rican Tody.}

Todies were common along the dry arroyo which passed by Santa Rita and emptied into the lagoon. In some places the rushing waters had cut their way through the gravelly clay soil leaving the banks from five to ten feet in height, with a fringe of trees and heavy undergrowth along the edge." Here the Todies delighted in darting about catching insects on the wing with marvellous swiftness, seldom ever missing. One day while following the arroyo in its windings, riding over the dry bed, I entered a secluded spot where the banks were perpendicular and large trees extended their branches across the top. Here I was greeted by the single call note of a Tody; it sounded like "psoop", and was generally repeated from five to ten times. A good imitation may be obtained by whistling it while the tongue is held against the roof of the mouth and the lips moved as though trying to speak the word at the same time. There, perched on a very long and slender sapling, not five feet from me, was a little ball of feathers, all puffed up, with dreamy eyes, and every time it uttered a note it would rise up on its feet as though by the effort. Cocking its head to one side with its bill pointing upward it would close first one eye, then the other. Every now and then its wings would open and close so swiftly that the motion was scarcely perceptible. Several tiny insects were quickly canght as, with a whirring sound, it launched, out into the air and returned to its favorite perch. Apparently the whirring sound is produced by the primaries, and the 
distinctly audible whistling sound, produced at the same instant as the whirring, is caused by the passage of air through the primaries. These sounds are produced only during flight, by the will of the bird, and by both sexes. While the little actor was amusing itself a second bird, presumably its mate, alighted beside it, and calling continuously for fully one minute, she suddenly dived, head downward, and disappeared into the side of the bank. I have seen several wonderful stunts performed by the feathered folk, and this one by a Tody easily takes its place among them. The bank had a smooth perpendicular face, the Tody was sitting a foot and a half from it, while four feet below her was the nesting hole with its two-inch entrance. One should really be acquainted with the little bird and the size of the entrance to its home in order to fully appreciate the wonderful control and keen sight exhibited when she dived and disappeared into the hole without disturbing even a tiny pebble at the entrance, bearing in mind that her passage through the air appeared as a green streak and without any hesitation at the entrance.

\section{TOLMARCHUS TAYLORI (Sclater). Porto Rican Petchary.}

February 25, 1925 I located a Petchary's nest, constructed of coarse sticks, neatly lined with horsehair and fine rootlets, deeply cupped, and placed at a fork on a horizontal branch of a Roma thirteen feet above the ground. It contained one egg which was rich salmon white spotted with large brown and chocolate spots and scrawls, heavier about the larger end. The nest measured 7 inches in diameter by 2.5 in depth. The eavity was 3 inches in diameter by 1.75 in depth. On March 1 it contained three eggs, similar in color and markings. March 20 there were two young and one egg. On the 21st there were three chicks in the nest, and the parent birds were very noisy and aggressive. Only insects were fed to the nestlings, and the task of supplying the demand was shared equally by the adults.

\section{BLACICUS BLANCOI Cabanis. Porto Rican Pewee.}

April 4, 1925 I made an excursion in the wild brushy country between Santa Rita and the south coast. At noon I. stretched myself out under a tree to rest, and observed a male Pewee catching insects. From somewhere, the female appeared and alighted on a branch directly above my head. The male, having seen her as she came, flew up, and almost at the same instant alighted beside her. Then followed an exchange of very softly uttered notes, "whup, whup, whup", so soft that they were scarcely audible. Slowly and quietly I shifted 
my position, and looking up I saw the female sitting on her nest, lengthwise with the branch. My first thought was how to reach the nest. A peculiar thing about a Turpentine tree is the way the thin outer skin peels and blisters but remains attached, which makes climbing difficult without the use of climbing irons. I found a way, however, by coaxing and pushing my little horse over the rocks until he was in a position that permitted me to grasp the lowest horizontal branch, by means of which I pulled myself up. The nest was placed on this same branch, about 14 feet from the ground and 6 feet from the trunk, but the brittleness of the wood made me doubt whether I should attempt to reach it. I finally decided to take the risk, and edged slowly, as smoothly as possible, forward until I could bend over and touch the nest. I measured the single egg, $.75 \times .55$ inch, white with a pinkish tint, marked sparingly about the larger end with lilac and brown spots and lines. The nest measured 2.5 inches in diameter by $1.75 \mathrm{in}$ depth, the eavity 1.80 in diameter by .75 in depth. It was composed entirely of green moss compactly woven together and completely covered on the outside with bits of "skin" taken from the turpentine tree, which camouflaged the nest so perfectly that it was absolutely impossible to detect it from below unless the parent bird was sitting. During the four or five minutes that I was busy taking the measurements the parent birds remained silent but kept close by, sometimes coming within three feet of me, twisting their heads from side to side with the crown feathers rising and falling as their beady little eyes followed my every movement. At the conclusion I froze on my precarious perch and whistled an imitation of their call note, at which they became very much excited, flitting from branch to branch with tails nervously twitching, and quite unexpectedly one of them flew to the nest and covered the single egg, two feet from my face, leaving only when my finger was about to touch its back.

\section{MIMUS POLYGLOTTOS ORPHEUS (Linné). Jamaican Mockingbird.}

I observed the first Mockingbird's nest on January 28, 1925 and the last one on April 16. During this period the birds were very active, the males fighting among themselves and reeking vengeance on all unsuspecting feathered folk who ventured too near their nesting sites. The females were as vicious as the males in the defense of their nests and young. Of fifteen nests which I observed in an isolated area, about 600 by 300 feet, planted to a species of acacia locally called "Roma", fourteen contained three eggs, and one four eggs. 
I was particularly impressed by the constancy of coloration and uniformity in shapes and sizes of the eggs. Every pair of nesting birds were matured adults and not birds of the year. There were never more than seven or eight pairs of birds in the immediate vicinity of the "Romas", which, with the similarity in eggs and nests, makes me believe that a few pairs raised two broods, and perhaps even three, in the season. The average measurement of 21 sets of eggs, consisting of 19 sets of three eggs each, and 2 sets of four eggs each, was $1.02 \times .73$ inches. A nest measured 10.0 inches in diameter by 4.0 in depth, the eavity being 3.0 in diameter by 2.75 in depth; it was composed of coarse sticks of "Roma", lined with horsehair and a few feathers. Young birds were fed caterpillars, small grasshoppers, and crickets, by both parents.

\section{VIREO LATIMERI Baird. Latimer's Vireo.}

May 18, 1925 I saw a female Latimer's Vireo completing a nest of soft grass blades while the male sang nearby. The nest was similar to that of the Jamaican Vireo, hanging from a forked branch ten feet from the ground.

18. VIREO OLIVACEUS OLIVACEUS (Linné). Jamaican Vireo.

I was particularly impressed by the difference between the songs of the vireos found on Porto Rico and those on St. Croix. Accustomed as I had become to the song of the St. Croix bird from hearing it many years, I was startled by the many variations in the song of the Porto Rican bird from the first time that I heard it, though their habits are identical. The song is a steady outpouring by the males from dawn until midday, becoming less frequent as the afternoon advances. I shall attempt to record five distinct song notes in writing as follows:

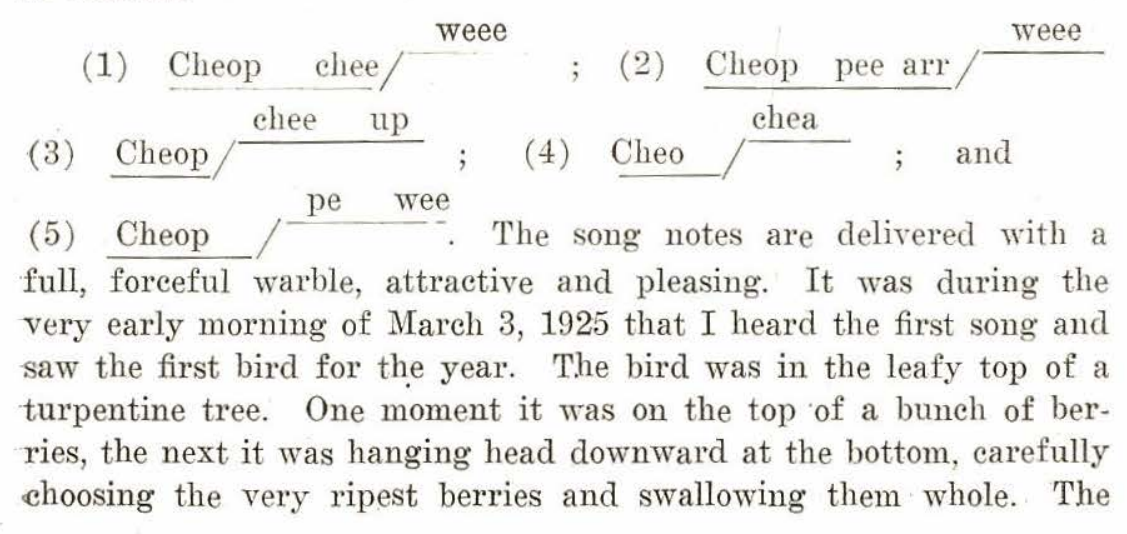


fleshy red skins of these berries are easily separated, during the process of digestion, from the hard indigestible stones, which are soon afterwards ejected through the mouth. May 17, 1925 I observed a nest hanging from the extremity of a long slender branch. The female was incubating while the male sang nearby. The nest was. about twenty-five feet from the ground. I saw no birds after August 15 .

\section{COEREBA PORTORICENSIS PORTORICENSIS (Bryant).} Porto Rican Honey Creeper.

Honey Creepers were not so numerous about Santa Rita as they were among the fruit gardens further inland, where they were always: heard singing lustily as they chased each other, stopping here and there to take a few pecks at a ripe mango. Or a male scolds passionately as he dashes after a female, and they are off, headed for the nearest wild cotton shrub, from which presently they may be seen returning, each with a tuft of cotton in its bill for the nest snugly bidden amongst a cluster of long green leaves at the end of a slenderbranch of a mango tree. During February and March I found several nests. One that I found on March 3 was about 30 feet up, an unusual height, at the end of a thin branch of a mango tree.

20. DENDROICA PETECHIA CRUCIANA Sundevall. Porto Rican Golden Warbler.

May 11, 1925 I found a nest of a Golden Warbler with three young. The nest was placed between the forked branches of an "acacia" bush that grew on the bank of the lagoon, two feet from. the water's edge, situated two and a half feet from the ground. Both parents were kept busy searching for fat worms and tender bugs to. satisfy the hungry little stomachs.

21. DENDROICA ADELAIDAE Baird. Adelaide's Warbler.

April 14, 1925 while riding through the grove of "Romas" I saw an Adelaide's Warbler with a tuft of cotton held in her bill. Reining in my pacer, I watched her as she flew to the nesting site. Waiting until she had gone in search of more material, I went to the spot and found an incomplete nest. On the 21st I examined the nest and found it empty with the pieces of two broken eggs on the ground beneath. The nest was made of cotton and soft grasses lined with horse hair and feathers, placed six feet up in the crotch of a threeforked slender upright branch.

April 27, 1925 I visited an area near Limón which was overgrown. with several species of eactus and thorny shrubbery. Here and there- 
the barrel cacti supported masses of climbing prickly vines. Riding by one of these clumps, the thorns caught in my shirtsleeve, and the resulting commotion seared an Adelaide's Warbler from her nest. The nest was six feet from the ground, and well concealed from view on all sides. It was made of dry grasses lined with hairs, back feathers of a Mockingbird, and soft, fine dry seedstalks of grasses, resembling the nest of the Golden Warbler. It measured 2.10 inches in diameter by 2.0 in depth, the eavity being 1.5 in diameter by $1.4 \mathrm{in}$ depth. The three eggs were white with a greenish tint, wreathed around the larger end with fine chocolate spots, the rest of the shell being sparingly spotted with brown. The eggs measured $.64 \times .48$; $.64 \times .48$, and $.63 \times .48$. During the time that I was busy at the nest the parent bird kept among the dense growth, occasionally showing herself as she seemed to glide about with little effort, calling a loud sharp "chip", similar to that of the Golden Warbler. I heard the song of several males, which is very pleasing and rich.

\section{HOLOQUISCALUS NIGER BRACHYPTERUS (Cassin).} Porto Rican Grackle.

On March 7, 1925 a nest I had observed being built contained one egg, on the 10th there were two eggs, and on the 17 th three eggs; this does not mean that the third egg was deposited on the 17th; I did not find the time to visit the nest between the 10th and 17th. On the 22nd the eggs were still unhatched. The nest was built in a crotch near the trunk of a "pine". The female would fly to a water hole or a drain to collect straw or other rotting vegetation covered with soft mud, and return to the nesting site with the material in her bill. Meanwhile, the male was never far away at any time, even in the air he could be seen trailing along not more than three feet behind her. He was a persistent love maker, and evidently knew that unless he kept an eye on his spouse she was likely to fall for a more ardent suitor, of which there were always a few around awaiting the chance. One habit she had that was very annoying to him was that she would fly up unexpectedly from the feeding ground, and proceeding for a couple of hundred of feet into the air, carried along by a series of slow, deliberate wing beats, she would describe a wide circle only to return and continue the interrupted meal. Meanwhile, the male, trailing behind her, went through a comic performance of short, rapid wingbeats, sailing for a short distance, pouring forth an unbroken medley of passionate songs. Then, after alighting, he proceeded to scold and strut around stiff-legged, tossing his head backwards one 
moment, or pressing his bill against his breast the next, erying pas-

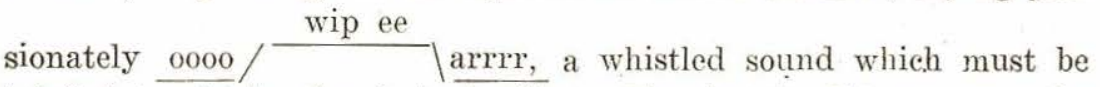
inhaled to obtain the desired effect. The female did not pay the slightest heed to any of his acting, merely aceepting all the love croonings and passionate outbursts showered on her by her chosen lord, as proof of his fidelity. The construction of the nest was undertaken by the female alone, while both sexes shared in the incubation.

April 23, 1925 I found two nests located in a "Roma" about eight feet from the ground. One nest contained three eggs with a bluish green ground color, splotehed and scrawled with umber and chocolate brown. The other nest was empty.

The same day (April 23) while crossing Hacienda "Limón" my attention was attracted by a flock of Grackles noisily announcing themselves from a large isolated clump of eactus. Veering off from the cowpath, I soon arrived at the spot where bedlam broke loose, and a hundred birds fluttered about me. The cluster of cactus was, more or less, 30 feet long by 12 wide and 10 high, and thickly matted together. Everywhere that I looked, from the top to near the ground, and for all the length and breadth of this patch, there were nests in all stages of construction, and six containing four eggs apiece. In all there must have been about thirty nests. One interesting thing I noticed was that a nest which contained four fresh eggs also contained a large amount of excrement from nestlings, a sign of its previous occupancy. It was impossible to determine, however, whether the same pair of adults were raising a second brood or if a strange pair had found the nest suitable to its needs.

23. TIARIS BICOLOR OMISSA Jardine. Carib Grassquit.

March 4, 1925 several Grassquit nests were being constructed. March 16 a nest was started and on April 2 it contained two eggs. A nest with one egg April 12 only contained two eggs when I examined it on the 15th; I am sure this nest was deserted. April 28 I found another nest with one egg. This was placed one foot from the ground in the crotch of a barrel eactus. Many other nests were placed among eacti, acacias, and in several instances among the trash at the bases of bunches of sugar cane.

24. LOXIGILLA PORTORICENSIS (Daudin). Porto Rican Grosbeak.

On May 18, 1925 I watched a pair of Grosbeaks constructing their nest, which was situated in a cluster of thorny vines, five feet from 
the ground. The incomplete nest was domed, with the opening at the side, similar to the nest of the Carib Grassquit, only larger, being about seven inches in diameter. One adult bird gathered the nest material, while the other followed close behind uttering a variety of call notes. 